\title{
REFERRAL PATTERNS IN CONSULTATION LIAISON PSYCHIATRY IN A TERTIARY HOSPITAL
}

\author{
V. V. Jagadeesh Settem ${ }^{1}$, Tejaswini Nandamuri², M. Vijaya Gopal ${ }^{3}$
}

${ }_{1}^{1}$ Assistant Professor, Department of Psychiatry, GSL Medical College and General Hospital, Rajahmundry, Andhra Pradesh, India. 2Junior Resident, Department of Psychiatry, GSL Medical College and General Hospital, Rajahmundry, Andhra Pradesh, India. 3 Professor and HOD, Department of Psychiatry, GSL Medical College and General Hospital, Rajahmundry, Andhra Pradesh, India.

\section{ABSTRACT}

\section{BACKGROUND}

Over the past two decades, research in psychiatry has identified the importance of Consultation-Liaison Psychiatry (CLP). However, this awareness has not yet brought significant change in research and particularly in clinical practice causing increased mortality and the morbidity. This retrospective case record analysis describes the Consultation Liaison patterns from January 2015 to December 2017 in the GSL General Hospital, a tertiary hospital in Rajanagaram. We wanted to evaluate the referral patterns to psychiatry department in a tertiary care hospital during the study period.

\section{METHODS}

A retrospective case record analysis of the psychiatric outpatient referrals from all the departments of GSL General Hospital from January 2015 to December 2017 was carried out. The parameters included were source of referral, reason for referral, symptomatology, relevant medical history, investigations and the provisional diagnosis. The results obtained were statistically analysed.

\section{RESULTS}

The findings of the present study show that prevalence of referrals has increased over the years. Other variables like marital status, lifestyle, and locality were compared but with no statistical significance. Psychoses, mood disorders, anxiety spectrum disorders and drug dependence formed the main junk of referrals and most of the organic part of the referrals is from the department of Neurology.

\section{CONCLUSIONS}

Our study showed that psychiatrists must create more awareness among their colleagues from other medical departments about the importance of liaison failing which could lead to incomplete treatment and continuous morbidity.

\section{KEY WORDS}

Patterns of Referrals, Consultation Liaison Psychiatry, Retrospective Case Record Analysis, Tertiary Hospital

HOW TO CITE THIS ARTICLE: Settem VVJ, Nandamuri T, Gopal MV. Referral patterns in consultation liaison psychiatry in a tertiary hospital. J. Evolution Med. Dent. Sci. 2019;8(27):2157-2161, DOI: 10.14260/jemds/2019/473

\section{BACKGROUND}

Over the past two decades research in psychiatry has identified Consultation-Liaison Psychiatry (CLP) as the guardian of holistic approach to the patient, underlining its pre-eminent role in management of patients who are admitted to a general hospital. The CLP objectives and operating procedures have evolved in recent years from administration of psychiatric treatment to integrating therapy into the bio-psycho-social model along the lines of the recommendation from an editorial in the Lancet "No health without mental health". [1] Hospital staff are confronted daily by physical/psychiatric multimorbidity with its extensive costs of suffering for patient and consumption of medical and economic resources. It is worth noting that psychiatric disorders, even when sub-clinical, worsen outcome, lengthen hospital stays and are associated with increased mortality and use of health service resources.

'Financial or Other Competing Interest': None.

Submission 04-05-2019, Peer Review 22-06-2019,

Acceptance 28-06-2019, Published 08-07-2019.

Corresponding Author:

V. V. Jagadeesh Settem,

74-8-5/1, F1, Mohana Apartments,

Prakash Nagar, Rajahmundry-533103,

Andhra Pradesh, India.

E-mail: svvjagadeesh@gmail.com

DOI: $10.14260 /$ jemds/2019/473
All over the medicine it is understood that psycho-social features influence aetiopathogenesis and prognosis of many chronic disease such as ischemic heart disease, diabetes, cancer and are crucial to management of the patient with multi-morbidity and unexplained medical symptoms, to the doctor-patient relationship, response to therapy, maintenance of illness behaviour and the onset of psychiatric complications in medical illness. This awareness, however, has not yet brought significant change in research and in the clinical practice, with its two-pronged interventions directed towards patients (in consultation) and towards physicians and surgeons in other hospital units (in liaison). This raises the question of creating multi-disciplinary teams with the psychiatrist mediating CLP integration and system. Furthermore, the unique features of CLP and the difficulties in implementing it are due to patients lacking both awareness of their own psychiatric disturbances and not personally requesting intervention. [2-6] The success of CLP intervention depends on various factors such as how the service is organised, the team experience and uniformity of intervention and ability to establish good lines of communication with the other specialists. The consultant psychiatrist, when called upon needs to coordinate, inform and educate, using standard procedures, guidelines and quality indicators. ${ }^{[7,8]}$ In the recent past emphasis on the importance of Consultation liaison psychiatry has increased. It not only widens the array of psychiatry services but also 
would significantly reduce the burden of morbidity on the patients and also facilitates more effective treatment from the primary physician. This retrospective file study describes the Consultation Liaison patterns during the study period in the GSL General Hospital, a tertiary hospital in Rajanagaram.

\section{Aim of The Study}

To evaluate the referral patterns to psychiatry department in a tertiary care hospital during the study period.

\section{METHODS}

We carried out a retrospective case record analysis of the psychiatric referral notes from all the departments of GSL General Hospital from January 2015 to December 2017. The Hospital has a total strength of about 1000 beds with almost all the specialities being covered. All the outpatient referrals were included. Institutional ethical committee clearance was obtained. The data related to the referral was obtained from the OPD registers, which are usually kept in the Psychiatry department. The referrals usually come in the form of referral notes via case sheets. The information along the following parameters was included: identifying data, source of referral, reason for referral, symptomatology, relevant medical history and investigations, provisional diagnosis, recommended action, and the response of the psychiatrist. The diagnosis in the referral letter was compared to the International Classification of Diseases, 10th edition, and to the final diagnosis in the case notes for agreement. Analyses were performed using the Statistical Package for Social Sciences. Descriptive statistics were used to summarize sociodemographic and clinical characteristics of the sample. As expected in most retrospective studies, some data were missing on occasional cases; hence the total number $(\mathrm{N})$ of various variables better is observed.

\section{Study Design}

Retrospective case record analysis.

\section{Study Tools}

Psychiatry OPD registers from January 2015 to December 2017.

\section{Study Area}

GSL Medical College and Hospital, Rajahmundry.

\section{Study Period}

Retrospective case record analysis from January 2015 to December 2017.

\section{Study Population}

All the outpatient referrals to the department of psychiatry during the study period.

\section{Statistical Analysis}

The referral patterns to the psychiatry department during the study period are enumerated using appropriate bar diagrams comparing them year wise, gender wise, department and the diagnosis wise. The total referrals are also compared with the total number of the out patients year wise during the study period, however the latter did not show any statistical difference with a $\mathrm{p}$ value of 0.066 .

\begin{tabular}{|c|c|c|c|}
\hline Year & Total N (\%) & Total No. of Outpatients & p Value \\
\hline 2015 & $162(8.4)$ & 1920 & \multirow{2}{*}{0.066} \\
\hline 2016 & $143(6.8)$ & 2100 & \\
\hline 2017 & $213(6.6)$ & 3204 & \\
\hline \multicolumn{3}{|c|}{ Table 1. Comparison of Outpatient Referrals with The Total } \\
Outpatients \\
\hline
\end{tabular}

\begin{tabular}{|c|c|c|c|}
\hline & $\mathbf{2 0 1 5}$ & $\mathbf{2 0 1 6}$ & $\mathbf{2 0 1 7}$ \\
\hline Organic Disorders & 45 & 28 & 47 \\
\hline Psychiatric Disorders & \multicolumn{1}{|l|}{} \\
\hline Psychoses & 19 & 8 & 21 \\
\hline Anxiety Disorders & 27 & 35 & 37 \\
\hline BPAD & 6 & 5 & 5 \\
\hline Depressive Disorders & 22 & 30 & 30 \\
\hline Drug Dependence & 16 & 20 & 38 \\
\hline $\begin{array}{c}\text { Others (Suicide, Behavioural Problems, tics, } \\
\text { Autism, Headache) }\end{array}$ & 9 & 3 & 7 \\
\hline Total & 21 & 14 & 28 \\
\hline & $\mathbf{1 6 2}$ & $\mathbf{1 4 3}$ & $\mathbf{2 1 3}$ \\
\hline
\end{tabular}

Table 2. Diagnosis Wise Distribution of the Outpatient Referrals to The Psychiatry Department
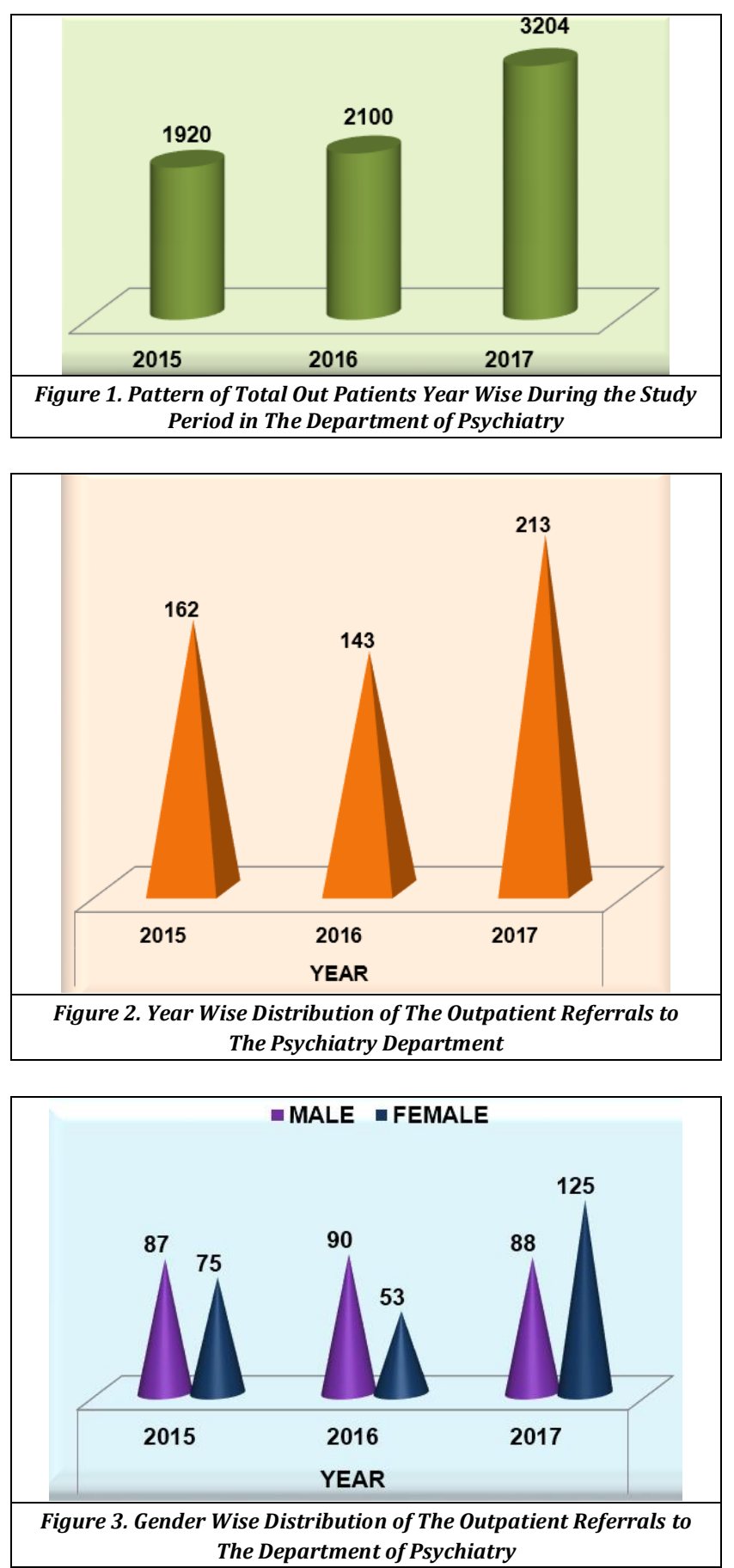

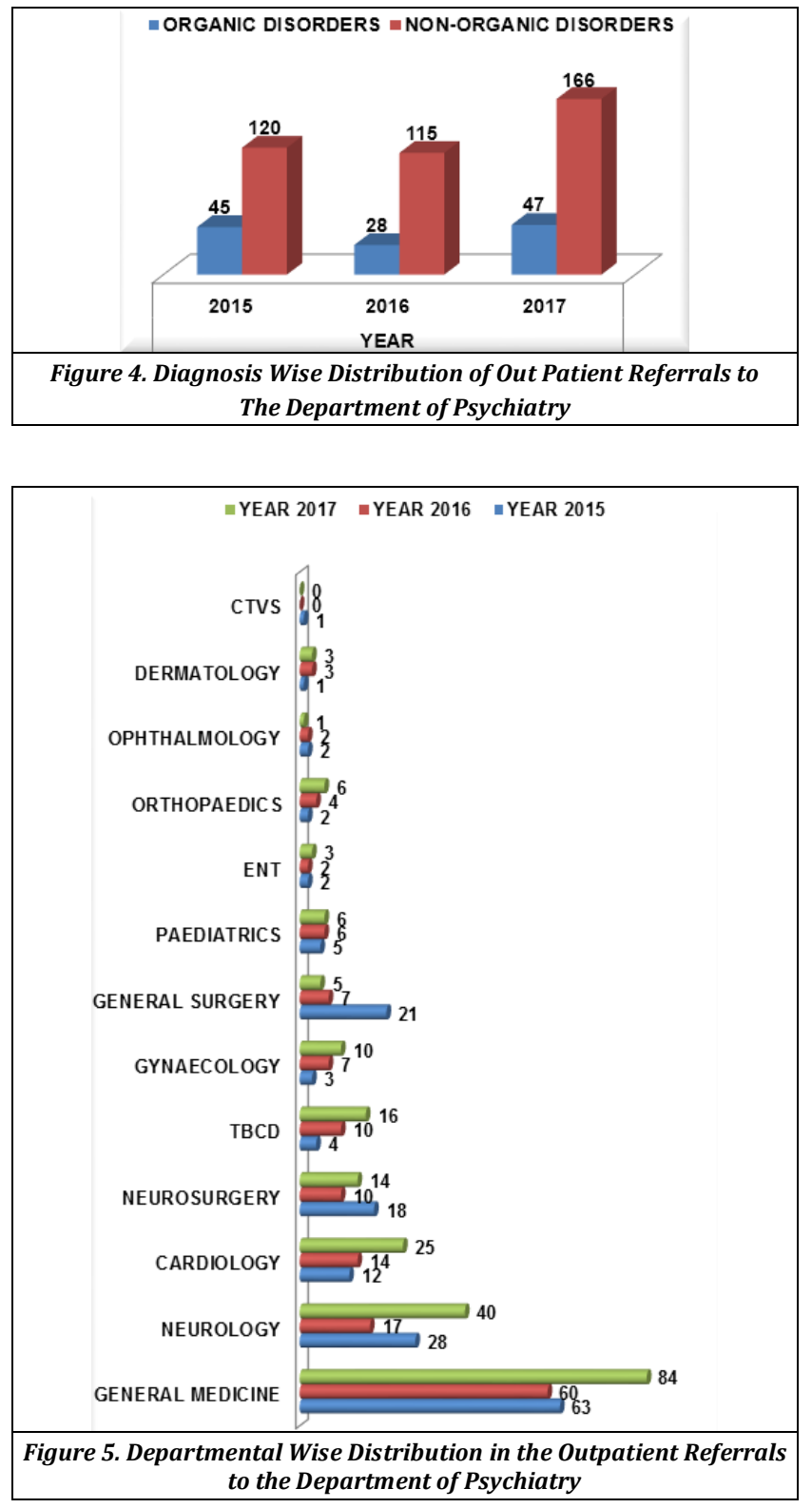

\section{RESULTS}

Pattern of total outpatients visiting the department year wise during the study period showed a gradual increase in the total number (N) from 1920 to 3204 from the year 2015 to 2017 (Figure 1). The total number of outpatient referrals to the department of Psychiatry also showed a gradual increase in the number from 162 to 213 during the study period with the year 2016 being an exception (Figure 2). This includes the referrals from all the medical and surgical departments in the hospital excluding the patients referred to the emergency triage and the inpatient wards. The number of visits by each individual patient on liaison basis to the department is not taken into consideration. On comparison of the total number of referrals with the total number of outpatients visiting the department year-wise, it has been observed that there has been a decline in the proportion of the referrals out of the total patients during the study period with the percentage shifting from 8.4 to 6.6. However, this difference in the values did not carry any statistical significance with the $p$ value of 0.066 (Table 1). The gender wise referrals to the department during the study period showed an increase in the female patients from 75 to 125 during the study period with the male referrals being more or less the same (Figure 3). The total number of referrals has been delineated according to their diagnosis with the primary diagnosis like psychosis, anxiety disorders, bipolar affective disorders, depressive disorders, drug dependence, mental retardation and others like Intentional self-harm, headache mentioned separately from the organic disorders which included seizures, poststroke, head injury and movement disorders (Table 2). The number of non-organic psychiatry diagnosis formed the major part of the referrals throughout the study period (Figure 4). This shows that most of the primary psychiatry disorder patients initially visit a primary physician or a surgeon before their psychiatry consultation. In the present study Anxiety disorders, Depressive disorders, Drug dependence, psychosis and other behavioural problems which also include Intentional self-harm formed the major proportion out of all the referrals. The total referrals are again analysed looking into the departments from which they were referred. The referrals from the department of general medicine and neurology formed a major part followed by the department of cardiology and neurosurgery (Figure 5).

\section{DISCUSSION}

The present study is done to look into the various patterns of the outpatient referrals to the department of psychiatry in a tertiary hospital during the study period. In the current study various variables like year wise, gender wise, diagnosis wise and the department wise referral patterns have been looked into. The year wise referral pattern to the psychiatry department on liaison basis showed a mild decline in the proportion but has not shown any statistical significance when compared to the total outpatients visiting the department during the study period $(\mathrm{p}=0.066)$. The gender wise referral pattern showed a relative increase amongst the female patients. Out of all the diagnosis the majority of the referrals are non-organic disorders with the prevalence of anxiety disorders, depressive disorders, drug dependence and psychoses and other behavioural disorders like Intentional self-harm being higher followed by organic disorders. This study findings are similar to those of an earlier study by Tariq et al (2002)[9] on consultation liaison psychiatry and its contributions to medical practice within a tertiary care teaching hospital. The number of anxiety and mood disorders is more common compared to psychotic spectrum disorders whereas it differs from the study in that the number of personality disorders is comparatively lesser. The present study clearly demonstrates that amongst the liaison cases to the psychiatry most of them are non-organic disorders and most of them visit a primary physician or a surgeon before being referred for a psychiatric evaluation. This finding also at the same time emphasises the need of liaison with psychiatry in any hospital to educate the fellow colleagues in identifying the common psychiatry disorders so the necessary intervention can be sought by the patient to minimise his/her morbidity. Also, as Consultation Liaison psychiatry is utilised it would also reduce the time and money spent by the patients at a tertiary hospital and will also save the valuable time of the other physicians and surgeons. Although there is some research in this area, it is of limited quality. Education could be provided to hospital doctors to facilitate recognition of mental illness. 
Collaborative screening of all the vulnerable groups will prevent inpatients from missing out on psychiatric care. CLP clinicians should use the knowledge gained in this review to provide quality engagement with their fellow consultants. The staggering needs of the population for psychiatric care and the limited number of available personnel and facilities have led to newer orientations for psychiatrists and other physicians. Consultation psychiatry is one of the new approaches and although its past history is scanty, its future is promising. The consultation situation should be particularly favourable for psychiatric intervention, at least in the dimensions of time and place.[10-14] The CLP service may thus be considered valid for implementing compliance with CLP interventions and evaluating their effectiveness. In particular referring to description of population and clinical variables sending requests by internet, performing consultation within $24 \mathrm{hrs}$. of request, writing down consultation findings will encourage communication within the multidisciplinary team, finally, one feature of the CLP service can be a link with the community health and social services, where information could be provided about treatment plans after discharge from the hospital.[15-18] According to observational studies for evaluating the referral patterns in a tertiary care hospital by Carla et al (2018), [19] a significant proportion of inpatients who were referred for a psychiatric consult were in view of alcohol withdrawal. Our study differs from the above mentioned, in that there were referrals with respect to other behavioural problems too. Other variables like marital status, lifestyle, and locality were compared but results were not found to be significant to prove association. In this study, a slight difference was observed among various departments with year, gender and diagnosis. The preponderance of male to female referrals was there in our study which has got reversed with progressive years showing mixed findings. Psychoses, mood disorders, anxiety spectrum disorders and drug dependence formed the main junk of referrals to our department which are primarily non-organic psychiatry disorders. This may be to a great extent because of the lack of awareness about the symptoms of the psychiatric illnesses among the general public. Partially this can also be attributed to the stigma in visiting a psychiatrist which is not an uncommon factor even in the educated and many medical personnel too. Moreover, stigma amongst the fellow medical colleagues to advice a patient to visit a psychiatrist can also be not neglected. In the current study, department wise majority of the referrals are from the department of general medicine and neurology followed by cardiology and Neurosurgery. This may be partially attributed to the patients' understanding of the neurosis, depressive symptoms as primarily secondary to a physical, neurological or cardiac cause. Also, most of the organic parts of the referrals are from the department of Neurology. Even today most of the places the psychiatric disorders are looked upon as neurological illnesses seeking for various investigations like brain imaging and an active search for an anatomical or neurological cause for majority of the psychiatric and behavioural problems. This is also one important reason for most of the dropouts during the follow up period in the psychiatric practice. This highlights the need to increase the awareness among the general public about functional disorders and the psychiatric services. And lastly the stigma among the public to visit a psychiatrist also plays a major role in adding to the infrequent and irregular utilisation of the psychiatric services which can gradually be to a great extent overcome through consultation liaison psychiatry.

\section{Limitations}

- The present study does not look into the inpatient referral patterns.

- It does not include the emergency case referrals.

\section{CONCLUSIONS}

Psychiatrists must create more awareness among their colleagues from other medical departments about the importance of liaison. If clinicians do not pay attention to psychiatric disorders, it could lead to incomplete treatment and continuous morbidity; [20-21] hence, careful evaluation of other psychiatric disorders in these people is highly recommended. [22-25] It also emphasises the need of the psychiatrists and other medical fraternity to promote awareness about the psychiatric disorders among the general public which can in turn reduce their morbidity and hospital stay to a great extent.

\section{REFERENCES}

[1] De Giorgio G, Quartesan T, Sciarma T, et al. Consultation-Liaison Psychiatry-from theory to clinical practice: an observational study in a general hospital. BMC Res Notes 2015;8:475.

[2] Onofa LU, Udoa OI, Fatiregun AA, et al. Clinical and demographic profile of patients using a liaisonpsychiatry service in a general hospital setting in Abeokuta, Nigeria. J Psychiatry January 2014;17:498502.

[3] Diefenbacher A. Implementation of a psychiatric consultation service: a single-site observational study over a 1-year period. Psychosomatics 2001;42(5):40410.

[4] Wiechers IR, Freudenreich O. The role of consultationliaison psychiatrists in improving health care of patients with schizophrenia. Psychosomatics 2013;54(1):22-7.

[5] Chadda RK, Deb KS, Mahapatra A, et al. Referral patterns in a consultation liaison psychiatry service in India: a comparison with the western world. General Hospital Psychiatry December 2018;15:35-9.

[6] Meyer F, Abbasi O, Kasick D, et al. Medical student experiences on consultation-liaison psychiatry rotations: a nationwide survey. Psychosomatics 2018;59(1):75-80

[7] Shaw RJ, Wamboldt M, Bursch B, et al. Practice patterns in paediatric consultation-liaison psychiatry: a national survey. Psychosomatics 2006;47(1):43-9.

[8] Cohen-Cole SA, Pincus HA, Stoudemire A, et al. Recent research developments in consultation-liaison psychiatry. General Hospital Psychiatry 1986;8(5):316-29.

[9] Al-Habeeb TA. A comparison of psychiatric referrals within the teaching hospital with those from primary care and general hospitals in Saudi Arabia. J Family Community Med 2002;9(3):57-65. 
[10] Lipsitt DR. Consultation-liaison psychiatry and psychosomatic medicine: the company they keep. Psychosom Med 2001;63(6):896-909.

[11] Ormont MA, Weisman HW, Heller SS, et al. The timing of psychiatric consultation requests: utilization, liaison, and diagnostic consideration. Psychosomatics 1997;38(1):38-44.

[12] Heinrich TW, Schwartz AC, Zimbrean PC, et al. Recommendations for training psychiatry residents in psychosomatic medicine. Psychosomatics 2014;55(5):438-49.

[13] Zaimes JM, Thompson TL 2nd. Opportunities for consultation-liaison (medical-surgical) psychiatrists to enhance residency recruitment. Psychosomatics 1994;35(5):423-6.

[14] Barsky AJ. A research agenda for outpatient consultation-liaison psychiatry. Gen Hosp Psychiatry 1993;15(6):381-5.

[15] Jimenez XF, Esplin BS, Hernandez JO. Capacity consultation and contextual complexities: depression, decisions and deliberation. Psychosomatics 2015;56(5):592-7.

[16] Martinez PC, Suratt CE, Chen DT. Cases that haunt us: the rashomon effect and moral distress on the consult service. Psychosomatics 2017;58(2):191-6.

[17] Smith GC, Clarke DM, Handrinos D, et al. Consultationliaison psychiatrists' management of somatoform disorders. Psychosomatics 2000;41(6):481-9.
[18] Holtz JL. Making a consultation service work: an organizational commentary. Psychosomatics 1992;33:324-8.

[19] Pezzia C, Pugh JA, Lanham HJ, et al. Psychiatric consultation requests by inpatient medical teams: an observational study. BMC Health Services Research 2018;18(1):336.

[20] Diehl A, Nakovics H, Croissant B, et al. Consultationliaison psychiatry in general hospitals: improvement in physicians' detection rates of alcohol use disorders. Psychosomatics 2009;50(6):599-604.

[21] Katon W, Gonzales J. A review of randomized trials of psychiatric consultation-liaison studies in primary care. Psychosomatics 1994;35(3):268-78.

[22] Pasnau RO. Consultation-liaison psychiatry: progress, problems, and prospects. Psychosomatics 1988;29(1):4-15.

[23] Shapiro PA, Lavakumar M. Measures of satisfaction with consultation-liaison services. Psychosomatics 2014;55(3):314

[24] Huyse FJ, Herzog T, Lobo A, et al. European consultation-liaison services and their user populations: the European Consultation-Liaison Workgroup Collaborative Study. Psychosomatics 2000;41(4):330-8.

[25] Borus JF, Barsky AJ, Carbone LA, et al. Consultation liaison cost offset: searching for the wrong grail. Psychosomatics 2000;41(4):285-8. 